\title{
Sequence Polymorphism in Prenatal Dental Development
}

\author{
ALPHONSE R. BURDI, STANLEY M. GARN, RICHARD L. MILLER, and \\ JERROLD M. NAGY \\ Department of Anatomy and Center for Human Growth and Development, University of \\ Michigan, Ann Arbor, Michigan 48104, USA
}

Sequence polymorphism is a well-known phenomenon of postnatal dental development. Individual sequence polymorphisms include the $\mathrm{dm} 2-\mathrm{c} / \mathrm{c}-\mathrm{dm} 2 *$ orders of eruption in the deciduous dentitions, and the M2-P2/P2-M2 and C-M2/M2-C eruption sequences in the permanent dentition (S. M. GARN and A. B. LEWIS, J Dent Res 36:992-995, 1957; S. M. GARN and A. B. Lewis, in Brothwell, D.R. (ed) Dental Anthropology, London: Pergamon Press, 1963; S. M. GARN, A. B. LEWIS, and J. H. Vicinus, $J$ Dent Res 41:717, 1962). Sequence polymorphism in prenatal human and infrahuman dental development has been explored only slightly, however, and the extent of sequence polymorphism in early prenatal development has not been quantified hitherto.

However, numerous dental sequence polymorphisms can be demonstrated in first trimester human embryos. Of 52 specimens between 14 and $58 \mathrm{~mm}$ in crown-rump length, considered normal by both gross and histologic inspection, departures from the $\mathrm{il}-\mathrm{i} 2-\mathrm{c}-\mathrm{dm} 1-\mathrm{dm} 2$ "textbook" sequence of development could be demonstrated in $25 \%$ of the sides considered. As shown in the table, such polymorphisms ranged from the i2-il order to the extreme dm1-i1 order, and included sequential variations in $c$ and $\mathrm{dm} 2$ as well. Left-right concordance averaged $65 \%$ for the $\mathrm{i} 2-\mathrm{i} 1$ and $\mathrm{c}-\mathrm{i} 1$ sequences and between 33 and $42 \%$ for the rarer $\mathrm{c}-\mathrm{i} 2$ and $\mathrm{d}-\mathrm{i} 1$ formation sequences.

As extrapolated from both size and stage-atdevelopment, "atypical" orders of early prenatal dental development were increasingly common in older and longer specimens $(\mathrm{CC}=$ 0.40 ), which is consistent with a wider range of dental "stages". Since the i1-i2-c-dm1-dm2 order was assigned in the absence of evidence

This investigation was supported in part by University of Michigan Faculty Research Grant Project 21.

Additional information available on request to authors.

Received for publication April 2, 1970.

* dm, deciduous molar; c, canine; $M$, molar; $P$, premolar; i, incisor. to the contrary, it is further likely that the true extent of sequence polymorphism in the 14 to $58 \mathrm{~mm}$ embryos is larger than that shown.

The correspondence between the prenatal sequence polymorphisms reported (as retrieved from IBM360 computer listings of individual tooth stages) and those previously known from postnatal studies is notable. It seems likely that some portion of postnatal dental development variability has its origins in earliest development and that current genetic models may now be extended backward into earliest embryonic life.

TABLE

Prenatal Deciduous Tooth Sequence Polymorphisms

\begin{tabular}{|c|c|c|c|c|}
\hline \multirow{2}{*}{$\begin{array}{c}\text { Prenatal } \\
\text { Formation } \\
\text { Sequence }\end{array}$} & \multicolumn{2}{|c|}{ Males } & \multicolumn{2}{|c|}{ Females } \\
\hline & No.* & $\%$ & No.* & $\%$ \\
\hline \multicolumn{5}{|c|}{$\mathrm{i} 1-\mathrm{i} 2 \ldots$} \\
\hline i1-i2-c-dm $1 \mathrm{dm} 2$ & 65 & 74 & 92 & 77 \\
\hline i1-i2-c-dm2-dm1 & 0 & 0 & 1 & 1 \\
\hline i1-i2-dm1-c-dm2 & 0 & 0 & 3 & 3 \\
\hline $\mathrm{i} 1-\mathrm{j} 2-\mathrm{dm} 1-\mathrm{dm} 2-\mathrm{c}$ & 1 & 1 & 0 & 0 \\
\hline i1-i2-dm2-c-dm1 & 0 & 0 & 1 & 1 \\
\hline i1-c-i2-dm1-dm2 & 3 & 3 & 0 & 0 \\
\hline i1-c-dm1-i2-dm2 & 2 & 2 & 1 & 1 \\
\hline i1-dm1-i2-c-dm2 & 1 & 1 & 0 & 0 \\
\hline \multicolumn{5}{|c|}{$\mathrm{i} 2-\mathrm{i} 1 \ldots$} \\
\hline $\mathrm{i} 2-\mathrm{i} 1-\mathrm{c}-\mathrm{dm} 1-\mathrm{dm} 2$ & 1 & 1 & 2 & 2 \\
\hline $\mathrm{i} 2-c-i 1-d m 1-d m 2$ & 7 & 8 & 5 & 4 \\
\hline i2-c-dm1-i1-dm2 & 0 & 0 & 3 & 3 \\
\hline $\mathrm{i} 2-\mathrm{dm} 1-\mathrm{i} 1-\mathrm{c}-\mathrm{dm} 2$ & 0 & 0 & 1 & 1 \\
\hline \multicolumn{5}{|c|}{$c-i 1 \ldots$} \\
\hline c-i1-i2-dm1-dm2 & 4 & 5 & 6 & 5 \\
\hline c-i1-dm1-dm2-i2 & 0 & 0 & 1 & 1 \\
\hline c-dm1-i1-i2-dm2 & 1 & 1 & 2 & 2 \\
\hline \multicolumn{5}{|c|}{$\operatorname{dm} 1-i 1 \ldots$} \\
\hline $\mathrm{dm} 1-\mathrm{i} 1-\mathrm{i} 2-\mathrm{c}-\mathrm{dm} 2$ & 1 & 1 & 0 & 0 \\
\hline dm1-dm2-i1-i2-c & 1 & 1 & 1 & 1 \\
\hline \multicolumn{5}{|c|}{$\mathrm{cm} 2-\mathrm{i} 1 \ldots$} \\
\hline dm2-i1-i2-c-dm1 & 1 & 1 & 1 & 1 \\
\hline
\end{tabular}

* Numbers of sides. See text for left-right concordance. 